\title{
REVENUE MANAGEMENT: RESOLVING POTENTIAL CUSTOMER CONFLICTS
}

\author{
Jochen Wirtz \\ NUS Business School \\ National University of Singapore \\ Singapore \\ Sheryl E. Kimes* \\ Cornell University School of Hotel Administration \\ Ithaca, NY, USA \\ sek6@cornell.edu \\ Jeanette Ho Pheng Theng \\ Banyan Tree Resorts and Spas \\ Paul Patterson \\ School of Marketing \\ University of New South Wales \\ Sydney, Australia
}

*corresponding author

\begin{abstract}
Revenue management is a sophisticated form of supply and demand management that helps a firm maximize revenue by balancing pricing and inventory controls. In recent years, an increasing number of firms have recognized the importance of revenue management in their ability to increase sales and profitability. When a firm that is fundamentally customer oriented also embraces revenue management, however, a series of customer conflicts can result and be detrimental to the firm's long-term success. This paper outlines these potential conflicts and explores various marketing and organizational strategies that can be used to resolve such conflicts.
\end{abstract}

KEYWORDS: customers, marketing, satisfaction, revenue management 


\section{INTRODUCTION}

Most of the past research on revenue (or yield) management has focused mainly on forecasting and optimization models (Bitran and Mondschein, 1995) and, more recently, on adaptation of revenue management to the specific needs in various industries, such as restaurants, car rental, transport and even health care services (Chapman and Carmel, 1992). Surprisingly, although most industries have been increasingly customer-centered (Schlesinger and Heskett, 1991), the customer seems to have been relatively forgotten in this stream of research. Little work has been done to explore: (1) the potential conflicts that arise from trying to integrate customer and revenue management orientation; (2) the way customers perceive revenue management strategies; and (3) how those conflicts could potentially be minimized or resolved. The objectives of this paper arc to explore these three issues and discuss how firms can effectively implement revenue management without compromising customer satisfaction.

\section{REVENUE MANAGEMENT ORIENTATION}

This section contrasts revenue management with customer orientation, provides a definition of revenue management, and outlines its importance to organizations. It also describes certain characteristics of organizations that make them particularly suited for revenue management, and then highlights conflicts that may arise from a revenue management orientation.

\section{What is revenue management?}


Revenue management is a sophisticated form of supply and demand management that balances pricing strategies with inventory management. It is essentially the process of allocating the right type of capacity to the right customer at the right time at the right price (Smith et al., 1992). It focuses the organization on maximizing profitability by applying disciplined tactics to forecasting consumer behavior at the micro-market level and control inventory availability at each price level (Cross, 1997).

Revenue management has led to increased profitability in a number of industries. For example, American Airlines reported that the benefits of revenue management were US\$1.4bn

over three years, approximately 4-5 per cent of revenue (Smith et al., 1992). Likewise, Hertz car rentals reported a 5 per cent increase in average revenue per rental with its revenue management system (Carroll and Grimes, 1995). Chevy s Mexican Restaurants achieved a 5.1 per cent increase in revenue attributable to revenue management (Kimes, 2003). With laudable results in the airline, car rental, hotel and restaurant industries, it is not surprising that the practice of revenue management is catching the interest of other industries such as shipping, performing arts, media and broadcasting services, professional services, and even hospital services. It has been shown that firms that employ a comprehensive revenue management system and over time have developed a strong revenue management culture, significantly increased revenues and profitability.

\section{Characteristics of organizations suited to revenue management}

Revenue management is particularly suited to industries with: 
(1) relatively finite capacity (once a car rental firm has rented out all its cars for the day, further demand cannot be met without substantial capital investment);

(2) perishable inventory - a feature of all intangible services (revenue from an unused cinema scat or hotel room is lost forever);

(3) micro-segmented markets (e.g. hotels and airlines are able to discriminate between a time-sensitive business traveler and a price-sensitive leisure customer);

(4) fluctuating demand (theatres can use revenue management to increase utilization during slow demand periods and minimize discount availability during high demand periods);

(5) services that can be sold in advance (airlines and rental car companies adopt reservation systems to sell capacity in advance);

(6) low variable to fixed costs ratios (this feature allows revenue management to ignore cost, and equate revenue maximization with profit maximization) (Kimes, 1989). Firms that exhibit all or most of these features have much to gain from revenue management.

\section{Potential conflicts arising from a revenue management orientation}

When a firm that is fundamentally customer oriented implements a revenue management system, a series of customer conflicts can arise that may be detrimental to the firm's long-term success. For example, in the airline industry, regular customers might expect to be accorded priority seat allocation during peak times. Such a strategy aims to secure a stream of future revenue from the customer by building a long-term relationship. In contrast, certain revenue 
management techniques restrict capacity availability for lower-paying customers during peak times. That means, that the highest-paying customers, not necessarily the most loyal customers, would get their seats confirmed during periods of excess demand.

For example, this has become increasingly problematic in the international airline industry where members of Qantas' frequent-flyer schemes typically found that they were unable to redeem points on flights in peak periods (Macken, 1996). This is especially frustrating when call center operators inform the frequent-flyer member that 'Yes, seats are available, but there is no allocation left for frequent flyers redemption tickets'. And the reason for this is simple revenue management systems can fairly accurately forecast not only the demand for any given flight, but also the percentage of last minute business passengers who are prepared to pay full fare. Such high-yielding passengers are the backbone of not only an airline's profitability, but also the profitability of most businesses that are characterized by fluctuating demand, finite capacity and perishable inventory. This intermittent availability of reward seats to regular customers can cause them to become frustrated and angry, and put their loyalty at risk. It is common that customers perceive the firm negatively when it executes inventory and pricing controls. This paper focuses on potential customer conflicts, discusses the potential reasons for these conflicts, and proposes various marketing strategies that can be employed to reduce such conflicts.

\section{POTENTIAL CUSTOMER CONFLICTS AND THEIR MANAGEMENT}

When a firm implements a revenue management program, conflicts with customers will invariably arise. Such conflicts may adversely affect customer satisfaction and may ultimately hurt the firm's long-term success. Such customer conflicts can arise when a firm implements 
variable pricing and inventory controls, and the customer believes that he/she has been treated unfairly (Kimes and Wirtz, 2002). Furthermore, fair behavior has been found to be essential to the maximization of long-run profits, and if a firm is to be successful with revenue management, customer loyalty must not be compromised.

For example, the price of an airline scat can be as volatile as commodities on the futures trading floor. On a scheduled night between Sydney and Melbourne, an economy class seat can range from around $\$ 149$ return to $\$ 480$. Whether passengers sharing the same row have paid \$149, $\$ 259$, \$350 or $\$ 480$ may merely reflect that fact that one booked a week earlier, was with a hotel or conference group, or was prepared to return at a later date, or stay over a weekend night. How do customers feel about such price discrimination when they become aware of it? Imagine Ron, who is travelling on business and paid \$320 for a hotel room, meets Kelly at the lounge and finds out that she had paid only $\$ 220$ for essentially the same room because she had indicated that she was on holiday when making her room reservation. In another common scenario, the same hotel may adopt bargaining, where the published rack rate is offered first and then varying levels of discounts are given only when the customer 'bargains'. Thus Sarah, who is also on leisure travel but paid \$260 for the same room, later finds out from Kelly that she could have bargained for a lower rate. Both Ron and Sarah may well perceive that the hotel has acted unfairly.

Perceived fairness is based on how customers view the reference transaction and the reference price (Kahneman et al., 1966). The reference transaction is how customers think a transaction should be conducted. For example, customers who book a seat on a flight assume that their scat will be available to them and may react negatively to overbooking. Similarly customers 
who book a three-night stay at a hotel and leave after two nights may be upset if they are charged an early departure fee. The reference price is how much customers think a product or service should cost. Reference prices come from market prices, posted prices and past experience. Fur both Ron and Sarah, the above scenario may mean that their reference price has just been reduced to Kelly's \$220. Thus, both would view their higher room rates as unfair, because they believe that the hotel has charged them a higher price to reap higher profits without increasing the customer's value. For example, customers may have seen a cruise advertised for \$2,000 per week and be upset if they are quoted a rate of $\$ 3,000$ when they try to book the cruise. Similarly, customers who pay \$25 per person for Sunday brunch may be upset when the Easter Sunday brunch costs $\$ 35$ per person.

Customers believe that the value to the firm should be equal to the value to the customer (Kahneman et al., 1966). If that relationship becomes unbalanced by increasing the value to the firm or by decreasing the value to the customer, the customer may view subsequent transactions as unfair. For example, if a golf course increases its greens fees for no apparent reason, it is increasing the firm value without increasing customer value. Customers are likely to view the transaction as unfair. Similarly, if a hotel imposes substantial restrictions on customers in exchange for only a somewhat lower price, customers will probably view the transaction as unfair too.

The principle of dual entitlement holds that most customers believe that they are entitled to a reasonable price and that firms are entitled to a reasonable profit. Three hypotheses emerge from that principle: 
(1) Customers feel that raising the price to maintain profits is fair. If costs increase, customers consider it reasonable for the price of the product or service to increase.

(2) Customers believe that raising the price to increase profits is unfair.

(3) If costs decrease, customers believe that it is reasonable for the company to maintain the same price. That may be because the customers are paying what they think they should, or because they believe management should reap the rewards of its cost-cutting efforts (Kahneman et al., 1966).

If the principle of dual entitlement holds true, revenue management may be perceived to be unfair. Customers generally view justified price differences as fair, but they view unjustified price differences to be unfair. If customers believe that the transaction is different from the reference transaction only in price, they may believe that the firm is receiving more than its reference profit and is behaving unfairly.

The next section discusses how revenue management strategies may cause customer conflicts, and suggest marketing strategies that can be employed to help reduce these conflicts, and integrate the firm's revenue management pursuits with its customer orientation. A summary of the potential causes of customer conflicts and the marketing strategies that are proposed to reduce them is provided in Table 1. Each conflict and its potential strategies for conflict reduction is discussed in the following sections.

\section{Pricing strategies}


Differential pricing strategies such as price discrimination, demand-based pricing and off-peak pricing may change the reference price and reference transaction and cause customers to view the current transactions as unfair, and may even perceive such differential pricing as price gorging. Apart from perceived unfairness, Ron and Sarah may also perceive a higher financial risk attached to their next purchase of any hotel service. This is because multi-tier pricing makes the reference price difficult to assess, avid people are thus uncertain whether they are getting a fair deal each time. Both perceived unfairness and the increase in perceived financial risk adversely affect the firm's objective of increasing customer satisfaction and gaining customer goodwill (Kimes and Wirtz, 2002). Strategies that avoid or reduce these conflicts resulting from the shifting of and uncertainty in reference prices and reference transactions are discussed next.

\section{Pricing strategies affecting the reference price}

When a firm sets a multi-tier price structure for essentially the same core service to maximize revenue, it must be able to justify the price differences. Several ways of charging different prices without incurring customer wrath are available. One method is to increase the reference price. Simply put, that means increasing the rack or full-fare rate and then expressing all other price points as discounts to this rack rate. It is not unusual to find businesses that are selling up to 95 per cent of their service at 'discounted' prices. Airlines advertise discounts off of their 'full' fare, while hotels offer discounts off of their 'rack' rate. The fact that only a small percentage of customers ever pay the 'full' fare or 'rack' rate is rarely mentioned.

Prospect theory applied to revenue management has shown that consumers perceive price differences expressed as discounts fairer than an economically identical price difference 
expressed as a surcharge or price increase (Kimes and Wirtz, 2002). Anita, who patronizes her hair salon on Saturdays, may perceive the salon as profiteering if she is faced with a weekend surcharge. However, Anita is likely to find her higher weekend price more acceptable, if the hair salon advertises its peak weekend price as the published price, and offers a $\$ 5$ discount for weekday haircuts. This would enable the firm to practice revenue management, while simultaneously maintaining customer satisfaction - having a high published price also helps to increase the reference price, and thus a sense of equity or fairness. Also, customers who receive a discount on weekdays may feel that they are now being rewarded for their weekday patronage.

Another method of justifying increased prices in the eye of the consumer is the use of rate fences. Properly designed rate fences allow consumers to self-segment on the basis of service characteristics and willingness to pay, and can help companies restrict lower prices to customers who are willing, to accept certain restrictions on their purchase and consumption experiences. Rate fences can help differentiate the prices offered to different market segments and can be physical or non-physical in nature (Hanks et al., 1992; Dolan and Simon, 1996). Examples of physical rate fences include view or seat location in a theatre, or size and furnishings of a hotel room, or a golf course can offer a higher-paying customer free golf balls, food and beverage discounts, and incentives for future play. The key is to increase the perceived value of the transaction. Non-physical rate fences include consumption, transaction and buyer characteristics. For example, they include staying a certain length of time in a hotel, playing golf in the afternoon, cancellation or change penalties, or booking a certain length ahead of time, etc. For example, Ron above may have felt that his $\$ 320$ was fair compared with Kelly's \$220, if Kelly had to prepay for her stay much earlier, was not allowed any refund or change of date, and had to stay a minimum of two nights. Airlines have used non-physical fences very effectively by 
associating various restrictions with the sales of discounted seats. The more restrictions the customer is willing to accept, the deeper the discount available. Customers are aware of the restrictions and can choose to take advantage of the discounts if desired. Rate fences can be highly effective in avoiding perceived unfairness, provided the rate fence is seen as clear and logical, and difficult to circumvent (Bennett, 1984).

Finally, the service or product can be bundled as part of a package, which effectively obscures the reference price (Ng et al, 1999). For example, when a weekend hotel special includes wine and meals, the customer may not know the price of the room. And, when a cruise line includes the price of air travel or ground transportation in the cruise package, the customer only knows the total price, not the cost of the individual components. Bundling usually makes price comparisons between the bundles in its components impossible, and thereby side-steps potential unfairness perceptions and reductions in reference prices.

\section{Pricing strategies affecting the reference transaction}

Firms employing revenue management often use demand-based pricing to build demand during off-peak periods. Customer conflicts may arise when such discounting practices attract inappropriate segments that change the nature of the service that regular customers have come to expect (Lovelock, 2001). For example, the business clientele of a fine dining restaurant may resent the noisy tour groups that have been attracted to lunch at greatly discounted prices. Or, a manager of a high-priced US public golf course reported that his regular customers who played during the week (normally a very low-demand period) were not at all pleased to find out they would be sharing the course with children attending a golf camp. 
Revenue management may also result in over-stretching of capacity, such as crowding business class or first class cabins through upgrading of overbooked passengers. Stretching beyond a certain level of capacity often changes the nature of the service and may result in inferior quality and customer dissatisfaction. Potential strategies to reduce these conflicts include spatially segregating customers, differentiating service benefits, and setting optimal capacity utilization guidelines.

\section{Spatially segregate customers and/or differentiate service benefits}

Spatially segregating the main customer segment and/or offering them exclusive and perceptible service benefits may help offset negative perceptions about the changed reference transaction. For example, restaurants can seat business clientele in a private section, and hotels can set aside dedicated check-in facilities and selected high floors for preferred guests. To illustrate, the general manager of an international five star hotel in Riyadh in Saudi Arabia explained 'We put the locals on floors 4 to 6, and international business guests on 9 to 11 because the local custom is to party to the early hours of the morning and, in the past, foreigners have complained bitterly'.

\section{Determine and set optimal capacity utilization}

Lovelock (2001) differentiates between maximum capacity and optimal capacity. The former is the physical limitation of the number of customers that can be accommodated at any one time. The latter is the ideal level of capacity utilization in which demand and supply are well balanced and customers receive the promised service level and experience. For example, a plumbing company should not plan to be fully scheduled, as there would be no slack to allow for 
unexpected, last minute and urgent demand, where a price premium might be charged. A selfstorage facility that is frequently running at 100 per cent occupancy would mean that many customers might not get the size of space that they requested ( 5 x 5, 5 x 10 etc.). A service firm must determine its optimal capacity utilization which balances revenue and enables it to deliver a level of service that meets or exceeds client's expectations. This optimal capacity level must then be set as a guideline for revenue management practices.

\section{Inventory control strategies}

Inventory control strategies such as restricted or preferred availability, overbooking and length of stay restrictions can change the balance of the reference transaction and can cause customers to view the transaction as unfair.

\section{Capacity restrictions}

Restricted or preferred availability restrictions may result in regular customers being turned away during periods of high demand, in favor of higher-paying occasional customers. For example, travel agents who provide year-round support to hotels or airlines may find themselves facing limited inventory allocations during peak periods when they most need the capacity to service their clients. This intermittent availability to regular customers is likely to result in customer dissatisfaction and endanger future repeat business. For example, Benny in Boston has been on an airline's waiting list for two months and later finds out that his colleague, who booked in Singapore, recently obtained an instant confirmation for the same flight. In Benny's case, he may view first-come, first-served queues as the norm. In the same vein, loyal rental car customers feel disappointed and angry when less loyal, but 'big ticket' customers receive 
preferential treatment by being chauffeured to their cars at airport long-term parking lots - in full view of other loyal customers (Fournier et al., 1998). Keeping inventory or bestowing overt preferential treatment for higher-paying passengers (or more profitable segments) may be viewed as opportunistic and thus unfair.

Many service firms have launched loyalty programs and built-in policy rules to give preferential availability to loyal or repeat customers. For example, some airline revenue management systems have incorporated 'loyalty multipliers' to regular customers' lower fares so that their reservation systems can accord preferred availability. Hotels offer loyal corporate accounts 'last room availability' despite their lower negotiated rates. While such policies afford regular customers 'special treatment' status, it does not address the dilemma faced when members of loyalty programs cannot secure bookings in peak periods. After guest surveys showed that blackout dates were a key dissatisfier among regular guests, Starwood Hotels and Resort redesigned its loyalty program which features no blackout dates for free stay redemptions.

\section{Overbooking}

Firms using revenue management typically use overbooking to protect themselves from anticipated cancellations and no-shows. Firms practicing overbooking are faced with the tradeoff between the opportunity cost of unused inventory and the cost of customer displacement.

If a customer is involuntarily displaced, the costs can be enormous, including the potential of future lost business, and poor word-of-mouth. Overbooking, however, is not necessarily incompatible with good service. If the cost of customer displacement can be reduced, companies can be more aggressive with their overbooking policies while maintaining (or 
increasing) customer satisfaction. For example, in the North American airline industry, the voluntary 'bump' system has met with great success (Anonymous, 1993). If a flight is oversold, the gate agents ask for volunteers willing to take a later flight in exchange for free (but restricted) tickets for future flights or cash payments. Many customers are eager to obtain the free travel, and the airlines are usually able to obtain more than sufficient volunteers for this program. The great majority (90 per cent) of 'bumps' are now voluntary, and both airlines and consumers are anticipate and back up overbooking programs with well-designed service recovery procedures, a standardized response to customers, and staff training to ease the burden on frontline staff. For example, American Airlines reduced their overbooking levels because of the strain it placed on frontline staff. Even though they were using a voluntary 'bump' system, had developed a standardized script for staff to use and had conducted effective training, frontline staff still felt uncomfortable with the procedures. American decided to forego the incremental revenue gain they could have obtained from more aggressive overbooking because of the long-term cost that it had on employees.

The airline experience illustrates the components of a well-designed overbooking service recovery system. First, the choice to be displaced should be voluntary if possible. Some customers may be willing to be displaced if compensated for the inconvenience. Secondly, advance notice of the displacement situation should be given so that customers can make alternative arrangements (or even better, the company should make the alternative arrangements for the customer). Thirdly, frontline employees and customers should be educated about the benefits of overbooking. For example, Singapore Airlines tells its frontline employees and passengers that overbooking is practiced to enable more passengers to enjoy an early confirmation on their preferred flight (Ho, personal experience, 2003). Finally, a substitute 
service should be offered which minimizes customer exposure to a competitor's service. For example, a Westin beach resort which has occasional oversales offers guests departing the next day the option of spending the last night in a luxury hotel near the airport or near the city at no cost. Guest feedback on the free room, the upgraded service, and a night in the city after a beach holiday has been very positive. Employees are also more comfortable handling such overbooking situations, as affected guests are satisfied and happy. From the hotel's perspective, the cost of the move only includes a one-night stay in the luxury hotel instead of turning away a multiple-night guest arriving that day (Ho, personal experience, 2003).

\section{Length of usage restrictions}

Length of stay restrictions are often used as part of a revenue management strategy. For example, a hotel may impose a three-day minimum length of stay for certain discounted rates. If a customer checks out early, some hotels will impose an early departure fee on that customer. Not surprisingly, this policy often meets with customer outrage. Similarly, hotels that use maximum length of stay restrictions may face the problem of customers who would like to stay longer but at the discounted rate. A manager of a casino hotel in Las Vegas often has 'low-rollers' (low-spending gamblers) who want to extend their stay. In low-occupancy times, this is not a problem but, if the hotel is expecting a large number of 'high-rollers' (high-spending gamblers), the staff will physically remove the belongings of the low-rollers and change the locks on their rooms so they cannot return (Kimes, personal communication, 2003). While this is obviously an extreme case, hotels can reduce the negative impact of length of usage restrictions by pursuing other less obtrusive approaches such as having the customer initial the departure date upon 
check-in, by having a clearly communicated policy for all reservations, and by explaining rate implications associated with shortening or lengthening the stay.

Length of usage restrictions are applicable to a variety of industries, including the restaurant business. For example, while most restaurants do not explicitly restrict customer dining times, they may seek to control dining duration implicitly in an attempt to increase table turnover and profit. If not done carefully, customers may feel rushed, and dissatisfaction may result. The author of a recent Wall Street Journal article described how busboys attempted to remove his still unfinished meal from the table, and his general dissatisfaction with the rushed dining experiences at several high-priced New York City restaurants (Bhatia, 2002). While increasing the table turnover rate is desirable, restaurant operators must do so carefully, since creating customer discomfort is a poor long-term strategy.

To conclude, companies implementing revenue management must consider how it will affect customer reference prices and transactions, and ensure that customer perceptions of fairness are not adversely affected. By designing pricing and inventory control strategies with customers in mind, companies can reduce customer dissatisfaction while increasing firm revenue.

\section{SUMMARY AND CONCLUSIONS}

The recognition that customers place different values on services has changed the way many service organizations set prices. By using demand-based pricing, good market segmentation and improved service packaging, service firms can increase price while 
maintaining or improving customer satisfaction. This paper has addressed the fundamental conflicts that arise when a firm simultaneously adopts customer orientation and revenue management practices. Because revenue management is usually implemented with direct revenue and profitability goals in mind, its indirect impact on customers seem to have been relatively forgotten. It is argued that revenue management may alienate customers unless the firm carefully addresses potential problems in advance.

The paper then outlined a series of actions that firms can implement if revenue management programs are to avoid undermining the firm's crucial customer orientation efforts. In other words, revenue and customer orientations can coexist, but only if top management acknowledges potential conflicts and is prepared to commit resources to rectifying the problems. 'Top' management is emphasized because pricing is typically the domain of a sales and marketing division, customer service and with it a heavy focus on customer orientation often rests with operations. To resolve the conflicts outlined in this paper successfully, each of these functional groups must understand the need for an integrated approach, and must be involved in implementing and practicing revenue management. 
Table 1. Strategies to reduce customer conflicts caused by revenue management.

\begin{tabular}{|c|c|c|}
\hline $\begin{array}{l}\text { Revenue management } \\
\text { practice }\end{array}$ & Potential customer conflicts & $\begin{array}{l}\text { Marketing strategies to } \\
\text { reduce conflicts }\end{array}$ \\
\hline \multirow{3}{*}{$\begin{array}{l}\text { Pricing strategies affecting } \\
\text { the reference price }\end{array}$} & -Perceived unfairness & -High published price \\
\hline & -Reduction in reference price & $\begin{array}{l}\text {-Physical and non-physical } \\
\text { rate fences }\end{array}$ \\
\hline & -Perceived financial risk & -Bundling of services \\
\hline \multirow[t]{2}{*}{$\begin{array}{l}\text { Pricing strategies affecting } \\
\text { the reference transaction }\end{array}$} & $\begin{array}{l}\text {-Change in nature of the } \\
\text { service }\end{array}$ & $\begin{array}{l}\text {-Spatially segregate } \\
\text { customers }\end{array}$ \\
\hline & Reduction in service quality & $\begin{array}{l}\text {-Differentiate service benefits } \\
\text {-Determine and set optimal } \\
\text { capacity limits }\end{array}$ \\
\hline Inventory Control & -Perceived unfairness & $\begin{array}{l}\text {-Preferred availability } \\
\text { policies for loyal customers }\end{array}$ \\
\hline -Capacity restriction & $\begin{array}{l}\text {-Perceived lack of customer } \\
\text { appreciation }\end{array}$ & $\begin{array}{l}\text {-Well-designed service } \\
\text { recovery programs }\end{array}$ \\
\hline -Overbooking & $\begin{array}{l}\text {-Perceived change in the } \\
\text { nature of the service }\end{array}$ & $\begin{array}{l}\text {-Clear communication and } \\
\text { positioning of length of stay } \\
\text { usage restrictions }\end{array}$ \\
\hline -Length of usage & & \\
\hline
\end{tabular}




\section{REFERENCES}

Anon. (1993) 'Simon says', Scorecard, The Revenue Management Quarterly. First Quarter, 1012.

Bennett, D. J. (1984) 'Discount fare market research 1981-83', 63rd Annual Meeting of the Transportation Research Board, January, 2.

Bhatia, P. (2002) 'Hurry up and eat", Wall Street Journal, 21st June, W1 and W6.

Bitran, G. R. and Mondschein, S. V. (1995) 'An application of yield management to the hotel industry considering multiple day stays', Operations Research, 43, 427-430.

Carroll, W. J. and Grimes, R. C. (1995) "Evolutionary change in product management: experiences in the car rental industry', Interfaces, 25, 5, 84-104.

Chapman, S. N. and Carmel, J. I. (1992) 'Demand/capacity management in health care: an application of yield management', Health Care Management Review, 17, 4, 45-54.

Cross, R. G. (1997) Revenue Management - Hard-core Tactics for Market Domination, Broadway Books, New York.

Dolan, R. J. and Simon, H. (1996) Power Pricing, The Free Press, New York.

Fournier, S., Dobscha, S. and Mick, D. G. (1998) 'Preventing the premature death of relationship marketing', Harvard Business Review, 76, 1, 42-51.

Hanks, R. B., Noland, R. P. and Cross, R. G. (1992) 'Discounting in the hotel industry, a new approach', Cornell Hotel and Restaurant Administration Quarterly, 33, 3, 40-45. 
Kahneman, D., Knetsch, J. L. and Thaler, R. H. (1966) 'Fairness and the assumptions of economics', Journal of Business, 59, 285-300.

Kimes, S. E. (1989) 'Yield management: a tool for capacity-constrained service firms', Journal of Operations Management, 8, 4, 348-363.

Kimes, S. E. (2003) 'Revenue management: implementation at Chevys Arrowhead', Cornell Hotel and Restaurant Administration Quarterly, forthcoming.

Kimes, S. E. and Wirtz, J. (2002) 'Perceived fairness of demand-based pricing for restaurants', Cornell Hotel and Restaurant Administration Quarterly, 43, 1, 31-37.

Lovelock, C. H. (2001) Services Marketing: People, Technology, Strategy, 4th edn, Prentice Hall, Englewood Cliffs, NJ, 426-427.

Macken, D. (1996) 'Fare go', Good Weekend Magazine, 19th March, 14-19.

Ng, I. C. L., Wirtz, J. and Lee, K. S. (1999) 'The strategic role of unused service capacity', International Journal of Service Industry Management, 10, 2, 211-238

Schlesinger, L. A. and Heskett, J. L. (1991) 'The service-driven service company', Harvard Business Review, 69, 5, 71-81.

Smith, B. C., Leimkuhler, J. F. and Darrow, R. M. (1992) 'Yield management at American Airlines,' Interfaces, 22, 1, 8-31. 